\title{
Adaptation and Validation of PATCH (Parental Attitudes toward Children with Handicapped) Scale in the Indonesian Parents
}

\author{
Farida Aini, Farida Kurniawati \\ Department of Educational Psychology \\ Universitas Indonesia \\ Depok, Indonesia \\ faridaaini16@gmail.com, farida1@ui.ac.id
}

\begin{abstract}
PATCH scale is an instrument to measure parents' attitude toward students with disabilities. It consists of three dimensions of attitude: cognitive, affective and behavioral intent or psychomotor dimension. In this study, PATCH scale was adapted into Bahasa version scale. Several stages were conducted to adaptation and validation PATCH scale process. 310 Indonesian parents in the inclusive primary school were involved in this study. The results indicated that the PATCH Bahasa version scale has a high level of reliability and adequate items to measure parents' attitude toward students with disabilities. The PATCH Bahasa version scale consists of 26 items. The confirmatory analysis describes an instrument model is fit. It can be used as an instrument to evaluate Indonesian parents' attitude toward students with disabilities in an inclusive education setting. Furthermore, the result of scale could be useful to design appropriate intervention to increase parents' positive attitude toward children with disabilities.
\end{abstract}

Keywords-parental attitude scale, reliability, scale validation, adaptation, disabilities.

\section{INTRODUCTION}

Parental involvement in the context of education in Indonesia is regulated in the Minister of Education and Culture No. 75/2016 about the School Committee. The school committee has functions in improving education services consisting of parents/guardians of students, school communities, and community leaders who care about education. It describes that parents have an active participation in the education process, including in the context of inclusive education.

Inclusive education is a process of strengthening the capacity of the education system for all learners, including for special with disabilities [1]. The definition is in line with Indonesian law of education No.80/2016, it is stated that individuals with disabilities have the same right to participate in education with other citizens effectively. Reference [2] explained that inclusive education provides opportunities for all students, including students with disabilities. This term confirms that education for all.
Parents involvement in inclusive education is very important to reach inclusive education purposes [3] - [9]. Reference [5] stated that parents' involvement in inclusive education is comprehensive, involving parents of students with disabilities and parents of regular students. However, several studies on parental views and perception on inclusive education have examined the attitudes of parents as a group. The study proved that perceptions of parents of students with disabilities and parents of regular students need to be considered to determine the success of inclusive education [10].

Furthermore, ref. [10] described that parents' perception of inclusive education and views towards students with disabilities have been both positive and negative. Triandis (1971), in [11] explained that perception about inclusive education and students with disabilities is part of attitude towards students with disabilities. Ref. [11] proposed three components of attitude toward students with disabilities. First, a cognitive dimension which is defined as knowledge or perception about students with disabilities. It is usually related to belief about the cause and effect of disability. Second, the affective dimension refers to emotional response toward students with disabilities, including empathy toward them. Lastly, behavioral intent refers to intention and self-efficacy to help students with disabilities.

In the context of inclusive education, parents may play an important role in developing their child's attitude and in increasing peer acceptance with their disabled friend. It describes the relationship between parents and children's attitude is required for improving awareness toward children with disabilities [12]. Moreover, parents who have a positive attitude towards students with disabilities will be able to help the formation of positive attitudes of their children towards students with disabilities than those who do not have a positive attitude. This positive attitude will ultimately affect their acceptance of students with disabilities [8], [10]. Ref [13] stated that one of the important factors in the formation of children's attitude is the influence of authority figures, in this case, the influence of parents' attitudes towards disabled children can impact their children's attitude. 
The study about parents' attitudes towards students with disabilities in Indonesia is still very limited. On the other hand, predict the parents' attitude toward children with disabilities in an inclusive education context is necessary. This study aims to adapt and validate of Parental Attitudes toward Children with Handicapped (PATCH) scale in the Indonesian parents in inclusive primary school. This scale can be used to be an instrument to evaluate the parents' attitude. In addition, the result of the scale can use to design an appropriate intervention for improving parents' attitude towards students with disabilities.

\section{METHOD}

The samples of this study were 310 parents in some inclusive primary schools in Jakarta and Depok. The demographic information included in this study is sex, age, education background, and marital status. Table 1 describes the demographics of participants.

TABLE I. CHARACTERISTICS OF PARTICIPANTS

\begin{tabular}{|l|l|l|}
\hline \multicolumn{1}{|c|}{ Variable } & & \multicolumn{1}{|c|}{ Percentage } \\
\hline \multirow{3}{*}{ Age Range } & Female & $78 \%$ \\
\cline { 2 - 3 } & Male & $22 \%$ \\
\cline { 2 - 3 } & $1 .<30$ years & $4 \%$ \\
\cline { 2 - 3 } & $2.30-39$ years & $56 \%$ \\
\cline { 2 - 3 } & $3.40-49$ years & $36 \%$ \\
\cline { 2 - 3 } & $4 . \geq 50$ years & $4 \%$ \\
\hline Education Background & Primary School & $4 \%$ \\
\hline & Junior High School & $9 \%$ \\
\hline & Senior High School & $42 \%$ \\
\hline & Diploma & $15 \%$ \\
\hline & Undergraduate & $26 \%$ \\
\hline Marital Status & Postgraduate & $4 \%$ \\
\hline & $<10$ years & $17 \%$ \\
\hline & $10-20$ years & $72 \%$ \\
\hline & $>20$ years & $11 \%$ \\
\hline
\end{tabular}

The PATCH (Parental Attitudes toward Children with Handicapped) scale was developed by Ref. [12]. It was developed to measure parents' attitude who have children involved in a survey of children's attitudes toward disability in Europe. The PATCH scale consists of 30 items which include three components of attitude toward students with disabilities proposed by Ref. [11], namely (1) cognitive component refers to knowledge and perceptual responses and verbal statement about student with disabilities (e.g., Handicapped children know how to behave properly), (2) affective component refers to parents' emotional responses including empathy towards students with disabilities (e.g., I would be embarrassed if a handicapped child invited my child to a birthday party), and (3) behavioral intent dimension defined as verbal statements related to behavior and overt action including self-efficacy to help students with disabilities (e.g., I would help a handicapped child who was being teased). Each component consists of 10 items and equal items between favorable and unfavorable items. It uses 5-point-Likert scale ranging from 0 (strongly disagree) to 4 (strongly agree). A higher score means a more positive attitude toward children with disabilities.

The brief version adapted and validated in Indonesian parents in inclusive primary schools. PATCH Bahasa version scale consists of 26 items and uses the Likert scale ranging from 1 (very disagree) to 4 (very agree). Reference [14] explained three good reasons not to use a five-point Likert scale. First, it can effect to response style bias. The respondent tendency to respond what the item was designed to measure. Second, it will take a longer time to complete, and lastly, five points Likert items are less stable than binary point Likert item such as four answer formats. There are differences numbers of items for each dimension of attitude toward students with disabilities (Triandis, 1971 in [11]). The brief version consists of seven items of cognitive dimension, nine items for affective dimension, and ten items for behavioral intent dimension.

There were three main processes conducted in this study. The first was the adaptation process consisting of five stages. The second was the data collection, and the last was psychometric properties of the instrument (reliability \& validity analysis).

According to [15], there were five steps that have been carried out for the process of adaptation scale. The first stage was the translation process. The translation process of PATCH scale into Bahasa involved one translator who has a high-level score in English (TOEFL score > 550) and understand about the concept of disabilities and inclusive education, works in the international organization and ever stayed abroad for several years. The second stage was the synthesis process. Synthesis process aims to synthesize the results of the translation. The third stage was back translation into English. This stage involved a person who has a high score level in English (TOEFL score > 550) but blind to the concept of inclusive education and children with disabilities.

The fourth stage was an expert committee review or expert judgment. It aims to consolidate all items which had translated and developed the pre-final of PATCH scale. There were three experts who were asked to do committee review in this study. Two of them are expert in the inclusive education field and one of them is a clinical psychologist. The expert committee is a critical role to make a decision about an instrument. The fifth stage was pretesting. PATCH Bahasa version scale was pretested to three parents who have a child in inclusive school.

Selecting sample and collecting data is the procedure after processing of adaptation scale. Sampling method in this study was non-random designed with judgmental sampling or purposive sampling. Ref. [16] explained that purposive sampling is a technique that the researcher as a judge decides people who can involve in the study. The researcher decided which school can provide information to achieve the purpose of this study. Four schools were selected. Two schools are public schools and others are private schools. Those schools have required information and were willing to be part of this study. The data collection was begun by coordinating with the principal in every school. The PATCH Bahasa version scale in booklet form distributed to students in all grade (first grade sixth grade). They were asked to give it to their parents at home. Parents were asked to complete the PATCH Bahasa version scale and requested to give it back to the teacher after completed it. This procedure for each school took some days. The parents were required to fill inform consents before complete the survey. The demographic information form 
included personal data of parents including, sex, age, education background, and marital status. In addition, demographic information of students such as sex, age, and grade. All respondents received a souvenir after completed survey. The data collection was conducted during March and April 2018.

Lastly, the reliability and validity analysis was conducted. It aimed to evaluate the reliability and find a model that consists of appropriate items to measure parents' attitude towards students with disabilities.

The data was analyzed using SPSS and Lisrel programs in order to evaluate the reliability and psychometric properties of the scale. The reliability for PATCH Bahasa version scale and for each dimension was calculated by Cronbach's Coefficient Alpha (Cronbach $\alpha$ ). In addition, the validity was analyzed through CFA (Confirmatory Factor Analysis) to examine the instrument model.

\section{RESUlT AND DiSCUSSION}

\section{A. Reliability}

The reliability analysis in this study employed the Cronbach $\alpha$ technique because: first, it is the most common technique to evaluate internal consistency, and second, previous research used Cronbach $\alpha$. Ref [17] stated that Cronbach $\alpha$ is a general formula to calculate the reliability of a test that has multiple-scored items (items with multiple scores, such as tests using a Likert scale). Ref [18] argued that a test which has a reliability coefficient ranging from 0.7 to 0.8 is good enough for most studies. The reliability of 30 item of PATCH Bahasa version scale is $\alpha=0.904$. There are three items (item no.21, item no. 23 and item no.17) with CRit value (Corrected Item-Total Correlation) less than 0.3 was deleted. 27 items have CRit values with a range between 0.3 - 0.6. Ref [19] declared that an item is good if it has a CRit value above 0.3 . Items that have a CRit value less than 0.3 are rated as bad items. In addition, one item (item no.22) was deleted in order to find a fit model in the cognitive dimension. As the results, there are 26 items which have high-level reliability and adequate items. The reliability of 26 item of PATCH Bahasa version scale is Cronbach $\alpha=0.917$. For each dimension has a high level of reliability as well, (1) Cognitive dimension which consist of 7 items have reliability Cronbach $\alpha=0.750$, (2) affective component which consists of 9 items have reliability Cronbach $\alpha=0.842$, and (3) behavioral intent component which consists of 10 items have reliability Cronbach $\alpha=0.823$. Table 2 shows some psychometric properties of the items of PATCH Bahasa version scale.

TABLE II. PSychometric Properties of PATCH BAHASA Version SCALE

\begin{tabular}{|l|l|c|c|c|c|}
\hline Subscale & \multicolumn{1}{|c|}{ Item } & $\mathbf{M}$ & SD & $\mathbf{r}_{\text {ite }}$ & $\boldsymbol{\alpha}-\boldsymbol{i}$ \\
\hline Cognitive & No.18 & 2.93 & .640 & .302 & .932 \\
\cline { 2 - 6 } & No. 20 & 3.00 & .525 & .523 & .929 \\
\cline { 2 - 6 } & No. 21 & 3.17 & .531 & .266 & .932 \\
\cline { 2 - 6 } & No. 22 & 2.27 & .691 & .366 & .931 \\
\cline { 2 - 6 } & No. 23 & 2.43 & .626 & .141 & .934 \\
\cline { 2 - 6 } & No. 25. & 3.27 & .521 & .554 & .928 \\
\cline { 2 - 6 } & No. 26 & 3.30 & .466 & .747 & .926 \\
\hline
\end{tabular}

\begin{tabular}{|c|c|c|c|c|c|}
\hline & $\overline{\text { No. } 27}$ & 3.10 & .481 & .369 & .930 \\
\hline & No. 28 & 3.33 & .547 & .631 & .927 \\
\hline & No. 29 & 3.33 & .606 & .536 & .929 \\
\hline \multirow[t]{10}{*}{ Affective } & No. 1 & 3.13 & .507 & .703 & .927 \\
\hline & No. 3 & 3.30 & .535 & .681 & .927 \\
\hline & No. 7 & 3.27 & .450 & .746 & .926 \\
\hline & No. 8 & 3.27 & .450 & .667 & .927 \\
\hline & No. 9 & 3.13 & .434 & .721 & .927 \\
\hline & No. 10 & 3.23 & .504 & .525 & .929 \\
\hline & No. 12 & 3.37 & .490 & .665 & .927 \\
\hline & No. 15 & 3.00 & .371 & .509 & .929 \\
\hline & No. 17 & 2.43 & .626 & .177 & .934 \\
\hline & No. 19 & 3.47 & .507 & .635 & .927 \\
\hline \multirow{10}{*}{$\begin{array}{l}\text { Behavioral } \\
\text { Intent }\end{array}$} & No. 2 & 3.27 & .521 & .676 & .927 \\
\hline & No. 4 & 2.80 & .610 & .406 & .930 \\
\hline & No. 5 & 3.13 & .346 & .588 & .929 \\
\hline & No. 6 & 3.13 & .346 & .588 & .929 \\
\hline & No. 11 & 3.03 & .556 & .598 & .928 \\
\hline & N0.13 & 3.30 & .535 & .726 & .926 \\
\hline & No. 14 & 3.13 & .571 & .752 & .926 \\
\hline & No. 16 & 3.40 & .498 & .737 & .926 \\
\hline & No. 24 & 3.13 & .681 & .584 & .928 \\
\hline & No. 30 & 3.47 & .571 & .516 & .929 \\
\hline
\end{tabular}

\section{B. Validity}

This study used CFA analysis. CFA analysis aims to confirm the preconceived theory [20]. Ref. [21] stated that CFA is used to test the factor structure that supported or confirmed by data or based on certain existing theoretical models. In this study, the number of factors that exist for the PATCH scale was emphasized based on three-components of attitude theory. The researcher wants to confirm the model of PATCH Bahasa version scale to attitude theory toward students with disabilities by ref. [11].

The indicators of the CFA value must be required the criteria of chi-square $\left(\chi^{2}\right)$ with a significance value more than 0.05 , the RMSEA value less than 0.08, and the Goodness of Fit (GFI) index above 0.91 [21]. Moreover, Ref. [20] declared that factor loadings range 0.30 and above are significant for a sample of 300 respondents. Twenty-six items of PATCH Bahasa version have factor loading with range $0.33-0.92$.

Factor analysis for cognitive dimension (Picture 1) has factor loading for seven items are $0.33,0.34,0.77,0.80,0.77$, 0.92 and 0.42 (range $0.33-0.92$ ), $\mathrm{p}$ value $=0.209, \mathrm{RMSEA}=$ 0.032 and $\mathrm{GFI}=0.99$.

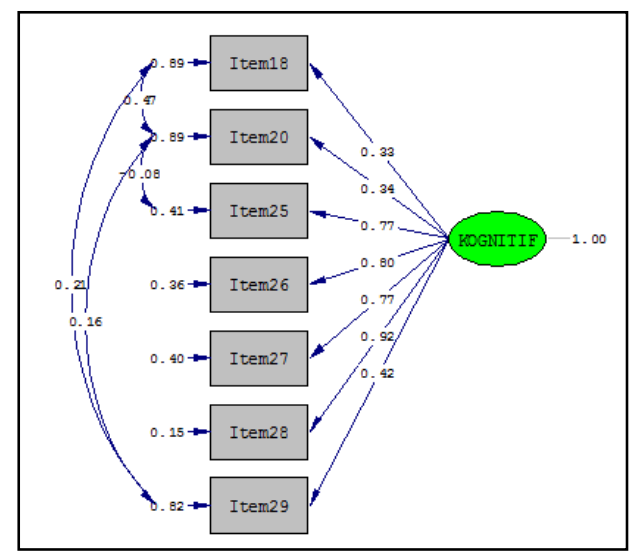

Fig. 1. Factor analysis for cognitive dimension. 
Factor analysis for affective dimension (Picture 2) has factor loading for nine items are $0.76,0.75,0.78,0.85,0.76,0.58$, $0.52,0.63$, and 0.64 (range $0.52-0.85$ ), $\mathrm{p}$ value $=0.132$, $\mathrm{RMSEA}=0.034$ and $\mathrm{GFI}=0.98$.

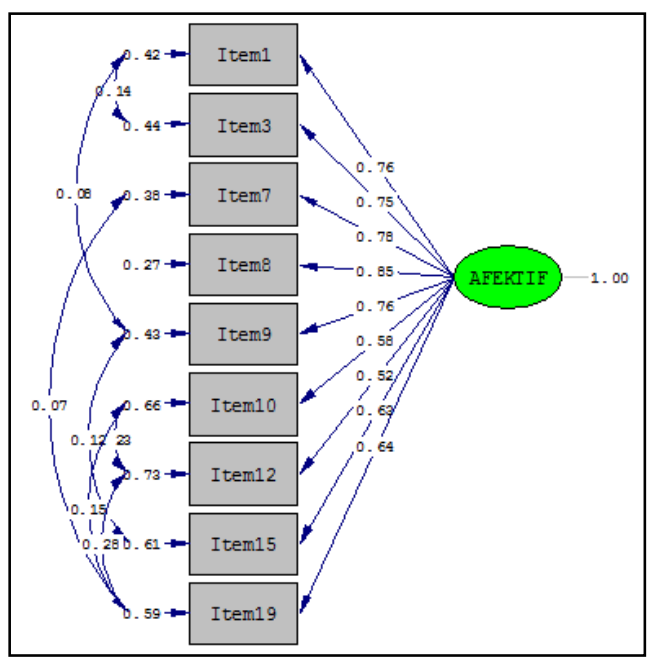

Fig. 2. Factor analysis for affective dimension.

Factor analysis for behavioral intent dimension (Picture 3) has factor loading for ten items are $0.48,0.39,0.56,0.65,0.62$, $0.82,0.68,0.83,0.42$, and 0.75 (range $0.39-0.83$ ), $\mathrm{p}$ value $=$ $0.074, \mathrm{RMSEA}=0.040$ and $\mathrm{GFI}=0.98$.

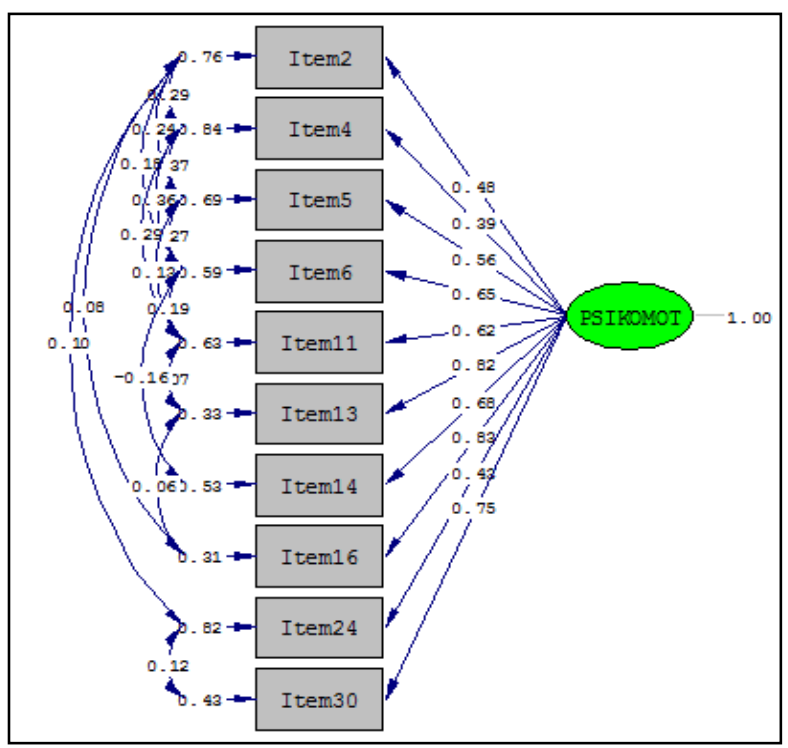

Fig. 3. Factor analysis for behavioral intent dimension.

Factor loading of items for each dimension showed that each item has good psychometric properties and able to explain the construct of the scale very well.

\section{DISCUSSION}

This study aims to adapt PATCH (Parent Attitudes Toward Disabled Children) scale in order to create an instrument to measure Indonesian parents' attitude towards children with disabilities. Understanding attitude toward children with disabilities is necessary for parents involved in an inclusive education setting. Improving parents' positive attitude towards students with disabilities indicates acceptance, support, and awareness in helping students with disabilities [10].

The PATCH Bahasa version scale was adapted through some processes. Ref. [15] explained the process of adaptation scale involving translation, synthesis, back translation, expert committee review and pretesting. In this study, the PATCH scale developed by ref. [12] was translated into Bahasa and analyzed by some experts. It was pretested to some parents in inclusive primary schools in Jakarta and Depok. The process was continued by validating and collecting data of the PATCH Bahasa version scale.

An instrument with good psychometric properties is necessary for research [7]. As the result, the PATCH Bahasa version scale consisting of 26 items has good reliability and psychometric properties. Reliability of scale and for each dimension show a high level of reliability with Cronbach $\alpha=$ 0.917. For each dimension with Cronbach $\alpha$ ranges from 0.750 to 0.842 . The result supported the three-component model in the PATCH Bahasa version scale based on attitude toward students with disabilities theory by ref. [11]. The instruments showed three-components with a distinction between cognitive component, affective component and behavioral intent component. The PATCH Bahasa version scale is multidimensional scale. The brief version adapted was not balance between favorable and unfavorable items for cognitive and affective dimension. It is different from the PATCH scale developed by [12] that have balanced items between favorable and unfavorable for each dimension.

According to demographic data of respondents, it is important to emphasize the total number of respondents and for each variable as well. Several characteristics are not balanced such as sex. Most of the respondents are female (mother). Ref. [7] described that gender is one of variables that influence attitude toward students with disabilities, mother known has a more positive attitude toward students with disabilities in an inclusive education context than father. Mothers of regular students prefer their children (regular students) to do interaction with their friends who are students with disabilities compared to fathers [22]. Moreover, the study showed the more they have interaction with students with disabilities, the more they have a positive attitude [23], [24].

Another variable is age. Most of the respondents were in 30 to 40 years old. This age is known as the adult age. Several research studies illustrate that parents' age does not affect their attitudes toward students with disabilities [25].

Regarding educational level in this study, parents have a wide variety of educational backgrounds, ranging from basic education to higher education (postgraduate). Some studies have found that there is no difference in attitudes of parents toward students with disabilities based on educational level [26]. On the other side, the study conducted by [6] proved that the parents' attitude towards students with disabilities is influenced by their educational level. It needs to be further examined, especially in the context of parents' attitude in Indonesia. 
Moreover, another demographic variable needs to be considered is marital status. A study which conducted on 372 parents at inclusive schools shows that marital status has a significant influence on parental self-efficacy to help students with disabilities [27]. Self-efficacy in helping students with disabilities in an inclusive education setting is a part of the behavioral intent dimension in the attitude theory [11].

Furthermore, this study involved parents in inclusive primary school, including parents with disabilities students. This study does not include the demographic variable of parents who have children with disabilities and those who do not. However, this issue described a limitation of the study. Further study can use the PATCH Bahasa version scale to compare the differences in the attitude between parents with special need students and parents with regular students. Ref. [8] described parents attitude toward students with disabilities were differences between parents who have a disabled child than who do not have. Parents hold different attitude related to the child's disability type. Previous research by [28] showed few parents of special needs students in Australia have a negative attitude toward inclusive education including students with disabilities. The literature review of 30 recent studies (2000-2015) conducted by [29] shows that there are different attitudes between parents of students with disabilities and parents of regular students toward students with disabilities. One of the influence variables is socio-economic status. In addition, the further study suggested increasing external validity that focuses on the 'outside' implication of the study [30]. It addresses to generalize research results to other levels of inclusive school such as in the kindergarten or in the senior high school.

The outcome of the PATCH Bahasa version scale can be used as an instrument to predict Indonesian parents towards students with disabilities in the context of inclusive education. The results of the instrument can be useful to design an intervention for parents in increasing their attitude toward students with disabilities in inclusive school. Intervention is one of the ways to change or form the attitude. Focus on environmental factors that consider direct and indirect experience with children with disabilities through intervention can improve more positive attitude [7]. By receiving the intervention parents have a chance to have direct or indirect experience with children with disabilities. Ref. [31] stated that attitude is formed by direct and indirect experience.

\section{CONCLUSION}

In conclusion, the PATCH scale in Bahasa version indicates high levels of reliability and adequate items to measure parents' attitudes towards children with disabilities. This scale is a useful instrument to design appropriate intervention to increase parents' positive attitude toward children with disabilities.

\section{REFERENCES}

[1] UNESCO, The Salamanca statement and the framework for action on special needs education. Paris, France, 1994.

[2] D. P. Hallahan and J. M. Kauffman, Exceptional children: Introduction to special education. Allyn and Bacon, 2006.
[3] Y. Leyser and R. Kirk, "Evaluating inclusion: An examination of parent views and factors influencing their perspective," International Journal of Disability, Development, and Education, vol. 51, no. 3, pp. 271-285, Sep. 2004.

[4] S. L. Neely and D. A. Dia, "Families of children with disabilities: A review of literature and recommendations for intervention," Journal of Early and Intensive Behavior Intervention, vol. 5, no. 3, pp. 93-107, 2008 .

[5] F. Beauregard, "Practice adopted by parents of children with dysphasia in inclusive primary school," Exceptionality Education International, vol. 21, no. 3, pp. 15-33. 2011.

[6] A. A. De Boer, S. J. Pijl, A. E. M. G. Minnaert, and W.J. Post, "The long-term effects of an intervention to promote attitudes of students toward children with disabilities," in Inclusion: A question of attitudes? A study on attitudes and the social participation of students with special educational needs in regular primary education, University of Groningen: Stichting Kinderstudies, Groningen, Netherlands, 2012, pp. $131-145$

[7] A. A. De Boer and V. Munde, "Parental attitudes towards the inclusion of children with profound intellectual and multiple disabilities in general primary education in the Netherlands," The Journal of Special Education, vol. 9, no. 3, pp. 179-187, Oct. 2014.

[8] M. K. A. Neyadi, "Parents attitude towards the inclusion of students with disabilities into the general education classroom," Thesis, United Emirate Arab University, UAE, 2015.

[9] L. S. Ary, "Parents' perception of a school-based inclusion program for their children with autism," Dissertation, Walden University, United States, 2017.

[10] N. Narumanchi and S. Bhargava, "Perceptions of parents of typical children towards inclusive education," Disability, CBR \& Inclusive Development, vol. 22, no. 1, May 2011.

[11] H. Triandis, J. Adamopoulos, and D. Brinberg "Theory and practice: perspectives and issues in the study of attitudes," in Attitudes and attitude change in special education, R. L. Jones. Reston: ERIC Publications, The Council for Exceptional Children, 1984, pp. 21-40.

[12] P. L. Rosenbaum, R. W. Armstrong, and S.M. King, "Parental attitudes toward children with handicaps: new perspectives with a new measure," Developmental and Behavioral Pediatrics, 1987.

[13] J. Gottlieb, L. Corman, and R. Curci, "Attitudes toward mentally retarded children," in Attitude and attitude change in special education, R. L. Jones. Reston: ERIC Publications, The Council for Exceptional Children, 1984, pp.143-156

[14] S. Dolnicar, B. Grun, F. Leisch, and J. Rossiter, "Three good reasons not to use five and seven point Likert items," In CAUTHE 2011: National Conference: Tourism: Creating a Brilliant Blend, School of Management, University of South Australia, 2011, pp. 1050.

[15] D. E. Beaton, C. Bombardier, F. Guillemin, and M. B. Ferraz, "Guidelines for the process of cross-cultural adaptation of self-report measures," Spine, vol. 24, no. 25, pp. 3186-3191, 2000.

[16] R. Kumar, Research Methodology. London: Sage Publications, 2011.

[17] A. Anastasi and S. Urbina, Psychological Testing. New Jersey: Prentice Hall, 1997.

[18] R. M. Kaplan and D. P. Saccuzzo, Psychological Testing: Principles, applications, \& issues. CA: Thomson Wadsworth, 2005.

[19] A. Field, Discovering Statistics using SPSS Third Edition. London: Sage Publications, 2009.

[20] J. F. Hair, W. C. Black, B. J. Babin, and R. E. Anderson, Multivariate Data Analysis, 7th ed. New Jersey: Pearson Prentice Hall, 2010.

[21] D. Cramer, Advanced Quantitative Data Analysis. New York: Mc-Graw Hill, 2003.

[22] E. Kalyvaam, M. Georgiadib, and V. Tsakirisc, "Attitudes of Greek parents of primary school children without special educational needs to inclusion," European Journal of Special Needs Education, vol. 22, no. 3, pp. 295-305, 2007.

[23] A. A. De Boer, M. Timmerman, S. J. Pijl, and A. Minnaert, "The psychometric evaluation of a questionnaire to measure attitudes towards inclusive education," European Journal of Psychology of Education, vol. 27, no. 4, pp. 573-589, Jan. 2012. 
[24] D. Radojichic and N. Jovanova, "Parents attitude: inclusive education of children with disability," International Journal of Cognitive Research in Science, Engineering and Education, vol. 2, no. 1, 2014.

[25] G. Balboni and L. Pedrabissi, "Attitudes of Italian teachers and parents towards school inclusion of students with mental retardation: the role of experience," Journal of Education and Training in Mental Retardation and Development Disabilities, vol. 35, no. 2, pp. 148-159, 2000.

[26] E. Tafa and G. Manolitsis, "Attitudes of Greek parents of typically developing kindergarten children towards inclusive education," Journal of Special Needs Education, vol. 2, no. 18, 2003.

[27] O. E. Afolabi, S. Mukhopadhyay, and H. J. Nenty, "Parents' involvement in inclusive education: An empirical test for the psychoeducational development of learners with special educational needs
(SENs)," Turkish Journal of Teacher Education, vol. 4, no. 1, pp. 50-65, 2015 .

[28] J. Elkins, C. E. Kraayenoord, and A. Jobling, "Parents' attitude to inclusion of their children with special needs," Journal of Research in Special Educational Needs, vol. 2, no. 3, pp. 122-129, 2003.

[29] G. Moutsinas, "Including students with disabilities: attitudes of typically developing children and of parents of children with and without SEN," The IAFOR International Conference on Education, 2016.

[30] D. S. Dunn, Statistics and Data Analysis for The Behavioral Sciences. New York: McGraw-Hill, 2001.

[31] S. Oskamp and P. W. Schultz, Attitudes and Opinions. New Jersey: Lawrence Erlbaum Associates, 2005. 